\title{
Separation Process of Tobacco Dust from Sand Impurities by Fluidized Fixed Bed
}

\author{
Arief Rahmatulloh ${ }^{1}$, Sandra Santosa ${ }^{1}$, Anang Takwanto ${ }^{1}$, and Atika Nabilla ${ }^{1}$ \\ ${ }^{1}$ Department of Chemical Engineering \\ Politeknik Negeri Malang \\ Soekarno Hatta 09 Street, Malang, 65141, East Java, Indonesia
}

\begin{abstract}
Tobacco dust is by-product of cigarette factory. The existence of impurities on tobacco dust in the form of iron sand (magnetite) and silica for about $10-\mathbf{2 0 \%}(\mathrm{wt} \%)$ makes tobacco dust belong to hazardous material. The threshold of sand impurities concentration on Tobacco dust is less than $5 \%$ (wt\%). One of the methods able to reduce the impurities of tobacco dust is separation process using fluidized fixed bed. Tobacco dusts before and after fluidized were analyzed with gravimetric method to find out the effect of separation process on the sand impurities concentration. The sand impurities concentrations on raw material of tobacco dusts are 28.47; 32.38; and $35.32 \%(w t \%)$. Further, the optimum gas flow velocity for separation process using fluidized fixed bed was achieved at $0.61 \mathrm{~m} / \mathrm{s}$. That velocity generated tobacco dust with the smallest sand impurities at $4 \%(w \mathrm{t} \%)$ in 120 minutes time operation. The subtraction of FTIR wavenumber after separation process $\left(497 \mathrm{~cm}^{-1}\right.$ to $493 \mathrm{~cm}^{-1}$ and $939 \mathrm{~cm}^{-1}$ to $925 \mathrm{~cm}^{-}$ 1) was denoted as the decrement of sand impurities concentration. Moreover, the loss of $\mathrm{Fe}-\mathrm{O}-\mathrm{Si}$ interaction indicated that the sand impurities concentration was successful to be reduced from the tobacco dust.
\end{abstract}

Keywords-Tobacco dust; Magnetite; Silica; Separation; Fluidized bed fixed.

\section{INTRODUCTION}

Tobacco dust is by-product of cigarette factory chopping process. The chemical content of dry tobacco dust consists of miscellaneous molecules i.e. nicotine, alkaloid, tar, organic proteins, carbohydrate, aromatic oil, and minerals (calcium, potassium, magnesium, sulphur), impurities of tobacco dust in the form of iron sand (magnetite) and also silica sand. If the tobacco dusts are ignored, it will pollute the air at the cigarette production process lines and also around the factory. The existence of impurities on tobacco dust in the form of iron sand (magnetite) and silica sand for about $10-20 \%$ (wt\%) makes tobacco dust belongs to hazardous material if it was blended with the air. According to WHO, If tobacco dust is inhaled continuously, it will decrease the function of the lungs. Furthermore, the tobacco dust buried in the lungs can cause fibrosis and tobaccosis disease. The threshold of sand impurities concentration on Tobacco dust is less than 5\% (wt $\%)$. Moreover, if the tobacco dust contains sand impurities less than $5 \%$ (wt \%), it will be able to reuse as raw material of cigarette production [1-3]. As a result, it is important for reducing or relieving the sand impurities from tobacco dust. One of the methods able to be carried out to reduce or relieve the impurities of tobacco dust is separation process with fluidized fixed bed.
Recently, fluidized fixed bed have been carried out in numerous numbers of industrial applications that involve the chemical, metallurgical, environmental and pharmaceutical sectors. In a fluidized bed, solid particles are maintained in suspension by uphill gas cascade to provide a liquid like gas - solid mixture. Fluidized bed gives many advantages to process such as improving contact efficiency, intensifying mass and heat transfer efficiencies, and being able to handle with a large number of particles and identical temperature distribution. Furthermore, fluidized beds have exceptional particle mixing and gas - solid contacting. A constant and low pressure drop in the bed that does not confide in the gas velocity ensures low-energy consumption. These factors have led to improve productivity and massive interest in the applications of fluidized fixed bed [4,5].

However, there are also diverse challenges correlated with fluidized fixed bed. One of the challenges involves the miscellaneous mixture of gas - solid with liquid - like role. This condition for beds with polydisperse particles is operated at high velocities. Whereas, the separation process on fluidized fixed bed provides an outlook for operate and scale-up fluidized beds. Separation process pursues in fluidized bed flourished in literature, which was primarily intended at operating factors. The operating factors are including particle properties (e.g. size, density, surface area) and fluidized gas properties (e.g. density, viscosity and velocity) [6]. As a result, the separation process in fluidized fixed bed could relieve the sand impurities on tobacco dust less than $5 \%$. In this research, the separation process was focused on velocity of the gas flow.

\section{EXPERIMENTAL}

\section{A. Materials and Instrumentation}

This research needs materials and instrumentations. The materials of this research are Tobacco dust from Indonesia's cigarette factory and aquadest, while the instrumentations needed are Fluidized Fixed Bed (Armfield, United Kingdom), Furnace (Nabertherm, L 3/12, Germany), Fourier-Transform Infrared (FTIR) Spectroscopy (Shimadzu, Prestige 21, Japan), Evaporating Dish, Glass Beaker (pyrex, $500 \mathrm{~mL}$, Singapore) and Magnetic stirrer.

\section{B. Pre-analysis of Tobacco Dust}

The sand impurities concentration of tobacco dust was analyzed using gravimetric method by furnace. First, the evaporating dishes which have been utilized as the container of the sample were pondered, further it were ignited in the oven at temperature $110^{\circ} \mathrm{C}$ for an hour. After that, it was 
pondered again to check the stable weight of evaporating dishes. Furthermore, the tobacco dusts were stirred to reassure that its compositions were uniform. The tobacco dusts were picked up from the sample container and were pondered about 10 grams. The sample was put at the evaporating dish and placed in the furnace to be incinerated. The temperature of the furnace was set on the $850^{\circ} \mathrm{C}$ for 3 hours because the pure tobacco dust would be vanished within the temperature. Furthermore, the product of the incineration was pondered and analyzed for the sand impurities level [7].

\section{Separation Process of Fluidized Bed}

Separation process of fluidized fixed bed was carried out by prepared 180 grams of tobacco dust as sample for every variation. The dimensions height of fluidization tube was $62 \mathrm{~cm}$ with diameter $20 \mathrm{~cm}$. Moreover, it was put in fluidized tube and the process was conducted at variation of velocity, namely $0.32 ; 0.41 ; 0.51 ; 0.61 ; 0.70$ and $0.79 \mathrm{~m} / \mathrm{s}$. The process also performed at variation of time on each velocity which was including 30; 60; 90 and 120 minutes respectively. The separation process was conducted for three times replication at each velocity variation. The product of the separation process has been collected by fine fabric which is placed on the top of the fluidized tube.

\section{Gravimetric Method}

The evaporating dishes which have been prepared before with pre-analysis method, served as container. Further, the product of the fluidization was pondered about 10 gram. The product was placed at the evaporating dishes and incinerated by the furnace. The temperature of the furnace was set at $850^{\circ} \mathrm{C}$ for 3 hours because tobacco dust will be vanished at that temperature. Moreover, the result of incineration process with furnace was pondered to found out the sand impurities concentration of tobacco dust.

\section{E. Fourier Transform Infra-Red Spectroscopy}

Fourier Transform Infra-Red Spectroscopy was conducted to found out the sand impurities existence on tobacco dust from both, the raw material of tobacco dust and the combostion product.

\section{RESULT AND DISCUSSION}

\section{A. Pre-analysis of Tobacco Dust}

Pre-analysis of tobacco dust was started with calibrated the evaporating dishes as the container of the sample with gravimetric method. The result of the calibration can be seen at Table I

TABLE I. MASS DATA OF EVAPORATING DISHES

\begin{tabular}{|c|c|c|c|}
\hline No & Initial (gram) & Constant (gram) & Weight Loss (wt\%) \\
\hline 1 & 41.86 & 40.83 & 2.46 \\
\hline 2 & 52.90 & 51.80 & 2.07 \\
\hline 3 & 108.65 & 108.61 & 0.03 \\
\hline
\end{tabular}

The table represented that there were weight loss on each evaporating dish. The weight loss associated with the evaporation of water crystal and water molecule of the evaporating dish. Hence the constant mass is the real mass of evaporating dish; as a result it was valid as container for gravimetric analysis. Further, the weight of tobacco dust placed in the furnace can be seen at Table II

\begin{tabular}{|c|c|c|c|}
\multicolumn{2}{c}{ TABLE II. } & MASS DATA OF TOBACCO DUST \\
\hline No & $\begin{array}{c}\text { Initial Mass } \\
\text { (gram) }\end{array}$ & $\begin{array}{c}\text { Final Mass } \\
\text { (gram) }\end{array}$ & Weight Loss (wt\%) \\
\hline 1 & 10 & 3.238 & 67.62 \\
\hline 2 & 10 & 3.532 & 64.68 \\
\hline 3 & 10 & 2.847 & 71.53 \\
\hline
\end{tabular}

Table II illustrates that there were also weight loss on each sample. The weight loss is due to the decomposition of substrate contained at the tobacco dust. The substrates decomposed are absorbed water, volatile compound, cellulose, hemicellulose, lignin, pectin, nicotine, and tar. This condition affiliated with thermal degradation process [8]. While the degree of ash can be calculated from the data of table 2 based on Equation (1)

Degree of Ash=(Weight of Ash/Weight of Sample)x100\% (1)

The degree of ash from sample 1 to 3 is $32.38 ; 35.32$; and $28.47 \mathrm{wt} \%$ respectively. This ash is affiliated with the sand impurities of tobacco dust which are silica and magnetite. The presence of silica and magnetite from tobacco dust make thermal oxidative degradation is exceptionally delayed. The mass residue of tobacco dust coincides to the dry silica and magnetite content $[9,10]$.

\section{B. Separation Result of Fluidized Fixed Bed}

The result of fluidization process for each variation of velocity can be seen at Figure 1.

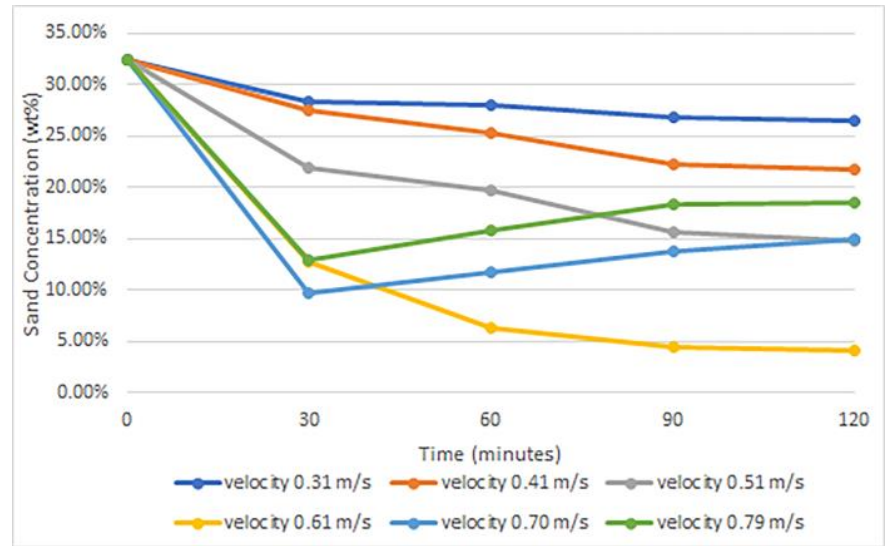

Fig 1. The Result of Separation Process by Fluidized Fixed Bed for Each Gas Flow Velocity

The separation process using the fluidized fixed bed conducted basically on the operating factors. Operating factors which has been varied was velocity of gas flow. Moreover, fluidization velocity was known as a main factor to the design and operation of fluidized fixed bed. It was not only expresses quantitatively the volume of drag force necessary to preserve solid particle in the gas phase of the fluidized bed, but also presents a reference to evaluate the intensity of fluidization $[6,11]$. The consecutive value of fluidization velocity is the aspect when the transition from 
stagnant bed to fluidized bed arises with enlarges the gas velocity. Further, the pressure drop of total bed persists approximately constant and the bed is begin switch over from being partially fluidized to fully fluidized [12].

Figure 1 is illustrates the determination of experimental fluidization velocity with increasing the gas flow. The fluidization product was analyzed with gravimetric method as pre-analysis of tobacco dust, hence it can be analyzed the sand concentration of tobacco dust after fluidization process. The raw material of tobacco dust which had been utilized as initial sample was tobacco dust with $32.38 \%$ (wt\%) of sand concentration. When the velocity was set for $0.32 \mathrm{~m} / \mathrm{s}$, the particles of tobacco dust which were initially languished, began to expand. This condition is known as incipient fluidization. When the gas velocity was increased, the particles of tobacco dust were suspended on the fluid which was passed by. On this condition, the granules of the particle were separated each other and made them easy to moved. Further, the character of tobacco dust particles was look like liquid which has high viscosity. This condition known as fluidized bed. When the gas velocity was set for $0.61 \mathrm{~m} / \mathrm{s}$, the distribution of particle was homogeneous hence the expansion on each particle was similar. This condition is known as homogenously fluidization. On the higher gas velocity $(0.70 \mathrm{~m} / \mathrm{s})$, it was emerged of bubble on the tube. The bubble made the particle distribution became inhomogeneous. As a result, the sand impurities' concentration was rose when the substrate fluidized in a long time. Furthermore, on the fastest gas velocity $(0.79 \mathrm{~m} / \mathrm{s})$ the bubble was inclined to coalesce and made a slug. On this condition the particle of tobacco dust was lifted up from the fixed bed almost all particles and made the sand impurities' concentration rose higher than latter velocity. This condition known as sludging fluidization[13]. From the Figure 1, it can be concluded that the optimum velocity for separation process by fluidized fixed bed was $0.61 \mathrm{~m} / \mathrm{s}$. That velocity was generated tobacco dust with the smallest sand impurities $4 \%(\mathrm{wt} \%)$ in the 120 minutes time operation.

\section{Analysis of Tobacco Dust with Fourier Transform Infrared Spectroscopy}

The FTIR spectra of initial tobacco dust and the optimum product of separation process of fluidized fixed bed can be seen at Figure 2. The FTIR spectra showed The following characteristic FTIR peaks of magnetite which were observed of both samples, the initial Tobacco Dust (A) and the optimum product of separation process using fluidized fixed bed (B). The Fe-O stretching vibration was recognized at 497 $\mathrm{cm}^{-1}$ and $493 \mathrm{~cm}^{-1}$ for sample A and B respectively. The subtraction of wavenumber after fluidization process (from $497 \mathrm{~cm}^{-1}$ to $493 \mathrm{~cm}^{-1}$ ) was denoted as the decrement of sand impurities concentration. The vibration of $\mathrm{Si}$ (-O-Si; $\mathrm{Si}-\mathrm{O}-)$ certified the presence of silica in the both samples, initial of tobacco dust and optimum product of fluidization process. The anti-symmetric vibration of Si-O-Si of both samples was observed at $1041 \mathrm{~cm}^{-1}$, while the symmetric stretching vibration of Si-O-Si was observed at $939 \mathrm{~cm}^{-1}$ and $925 \mathrm{~cm}^{-1}$ for sample A and sample $B$ respectively. The subtraction of wavenumber was also referred as the decrement of sand impurities concentration. Furthermore, the specific peak of the magnetite/silica bond as Fe-O-Si was detected at $565 \mathrm{~cm}^{-1}$ only on the sample A [14-16]. Significantly, the disappearance of Fe-O-Si on FTIR spectra of sample B indicated that there was no interaction between magnetite and silica. Hence the sand impurities concentration was successful to be reduced from the tobacco dust.

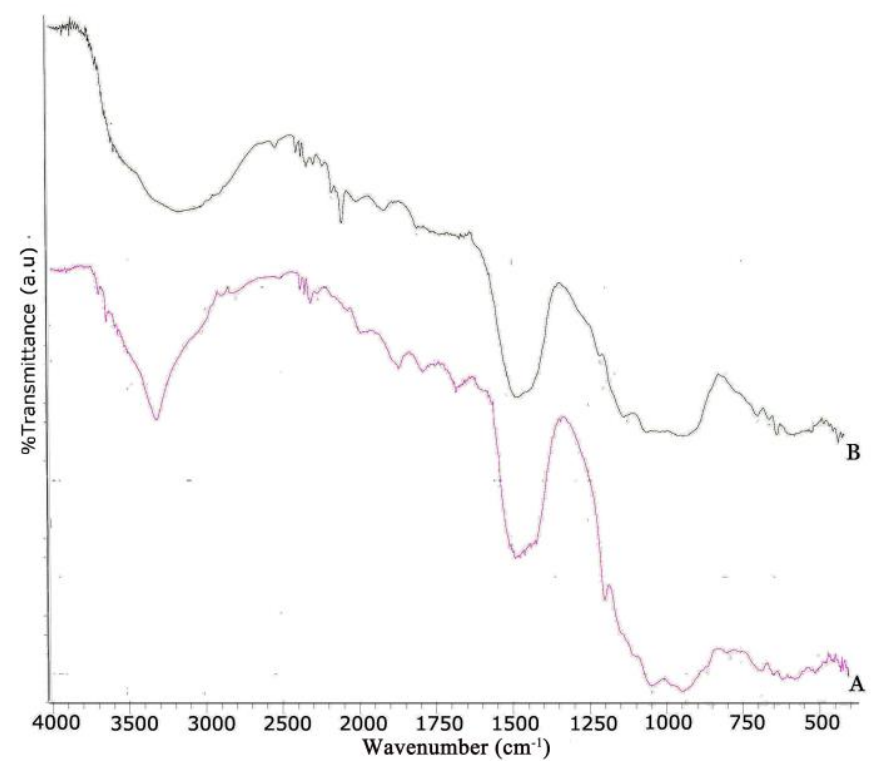

Fig 2. FTIR Spectra of Initial Tobacco Dust (A) and Optimum Product of Separation Process by Fluidized Fixed Bed (B)

\section{CONCLUSION}

The separation process of tobacco dust using fluidized fixed bed was success to reduce the sand impurities concentration. The optimum velocity for separation process was $0.61 \mathrm{~m} / \mathrm{s}$. That velocity generated tobacco dust with the smallest sand impurities $4 \%$ (wt $\%$ ) in 120 minutes time operation. The FTIR spectra confirmed that with the subtraction of wavenumber after separation process using fluidized fixed bed $\left(497 \mathrm{~cm}^{-1}\right.$ to $493 \mathrm{~cm}^{-1}$ and $939 \mathrm{~cm}^{-1}$ and $\left.925 \mathrm{~cm}^{-1}\right)$ and the disappearance of Fe-O-Si interaction. As consequent, it can be concluded that the sand impurities concentration was successful to be reduced from the tobacco dust.

\section{REFERENCES}

[1] Chloros, D., Sichletidis, L., Kyriazis, G., Vlachogianni, E., Kottakis, I., and Kakoura, M., 2004. Respiratory effects in workers processing dried tobacco leaves. Allergol Immunopathol (Madr). 32(6), pp.344351 .

[2] Valverde, JL., Curbelo, C., Mayo, O., Molina, CB., 2000. Shorter communication pyrolysis kinetics of tobacco dust. 78(9), pp.1-4.

[3] Banožić, M., Babić, J., Jokić, S., 2020. Recent advances in extraction of bioactive compounds from tobacco industrial waste-a review., Ind Crops Prod. 144(7).

[4] Wang, J., Shao, Y., Yan, X., and Zhu, J., 2019. Review of (gas) liquid-solid circulating fluidized beds as biochemical and environmental reactors. Chem Eng J. (xxxx), pp.121951.

[5] Zhao, K., Thunman, H., Pallarès, D., and Ström, H., 2017. Control of the solids retention time by multi-staging a fluidized bed reactor. Fuel Process Technol. 167, pp.171-182.

[6] Zhang, W., 2009. A Review of techniques for the process intensification of fluidized bed reactors. Chinese J Chem Eng. 17(4), pp.688-702. 
[7] Yang, Z., Zhang, S., Liu, L., Li, X., Chen, H., Yang, H., and Wang, $\mathrm{X}$, 2012. Combustion behaviours of tobacco stem in a thermogravimetric analyser and a pilot-scale fluidized bed reactor. Bioresour Technol. 110, pp.595-602.

[8] Zhou, S., Ning, M., Xu, Y., Hu, Y., Shu, J., Wang, C., Ge, S., Tian, Z, She, S., and He, Q., 2013. Thermal degradation and combustion behavior of reconstituted tobacco sheet treated with ammonium polyphosphate. J Anal Appl Pyrolysis. 100, pp.223-229.

[9] Monti, M., Hoydonckx, H., Stappers, F., and Camino, G., 2015. Thermal and combustion behavior of furan resin/silica nanocomposites. Eur Polym J. 67, pp.561-569.

[10] Rianna, M., Sembiring, T., Situmorang, M., Kurniawan, C., Tetuko, AP., Setiadi, EA., Priyadi, I., Ginting, M., and Sebayang, P., 2019. Effect of calcination temperature on microstructures, magnetic properties, and microwave absorption on $\mathrm{BaFe}_{11.6} \mathrm{Mg}_{0.2} \mathrm{Al}_{0.2} \mathrm{O}_{19}$ synthesized from natural iron sand. Case Stud Therm Eng. 13(1), pp.100393.

[11] Shao, Y., Ren, B., Jin, B., Zhong, W., Hu, H., Chen, X., and Sha, C., 2013. Experimental flow behaviors of irregular particles with silica sand in solid waste fluidized bed. Powder Technol. 234, pp:67-75.

[12] Wang, C., Zhu, J., 2016. Developments in the understanding of gassolid contact efficiency in the circulating fluidized bed riser reactor: A review. Chinese J Chem Eng. 24(1), pp:53-62.

[13] Zhang, K., Yu, B., Chang, J., Wu, G., Wang, T., and Wen, D., 2012. Hydrodynamics of a fluidized bed co-combustor for tobacco waste and coal. Bioresour Technol. 119, pp:339-348.

[14] Taufiq, A., Nikmah, A., Hidayat, A., Sunaryono, S., Mufti, N., Hidayat, N., and Susanto, H., 2020. Synthesis of magnetite/silica nanocomposites from natural sand to create a drug delivery vehicle. Heliyon. 6(4).

[15] Kuncaka, A., 2013. Impregnasi basah $\mathrm{Fe}^{3+}$ ke dalam silikat mesopori mcm-41-tersililasi. GANENDRA Maj IPTEK Nukl.16(1), pp:38-47.

[16] De Mendonça, ESDT., de Faria, ACB., Dias, SCL., Aragón, FFH., Mantilla, JC., Coaquira, JAH., and Dias, JA., 2019. Effects of silica coating on the magnetic properties of magnetite nanoparticles. Surfaces and Interfaces. 14, pp:34-43. 